\title{
Morphological Study on Electrochemical Sensor Based Polypyrrole by Scanning Electron Microscopy
}

\author{
G. González-Mancera ${ }^{1}$, J.L., Ramírez Reyes ${ }^{2}$, and H. Quintana Camacho ${ }^{3}$ \\ ${ }^{1}$ Instituto de Investigaciones en Materiales, Universidad Nacional Autónoma de México, \\ Ciudad Universitaria, México, D.F., 04510 \\ ${ }^{2}$ Instituto de Ingeniería, Universidad Veracruzana, Boca del Río, Ver., México, 94294 \\ ${ }^{3}$ Fac. de Ingeniería Química, Universidad Veracruzana, Boca del Río, México, 94294
}

Electrochemical sensors represent a fast and not expensive detection method of heavy metals, which have the negative impact toward human health and environment. A typical electrochemical sensor consists of a sensing electrode (or working electrode), and a counter electrode separated by a thin layer of electrolyte. Conductive polymers have many technological applications because they have a great variety of properties; they result from the monomer oxidation. Conductive polymers are materials with a redox behaviour, plus combined properties of metals and plastics. The application of conductive polymers like polypirrole in electrochemical sensors provides an alternative for detection of metal ions. The polypirrole develops a high electrical conductivity $10^{2} \mathrm{~S} / \mathrm{cm}$, similar to the In and $\mathrm{Sn}$, thermal stability, oxidation resistance, it is easy to obtain from aqueous solutions and organic solvents by chemical or electrochemical polymerization [1].

This paper presents the characterization by Scanning Electron Microscopy (SEM) and chemical X-ray microanalysis (EDS) of four composites for electrodes based on mixture of commercial graphite, Opuntia Ficus or Mexican Nopal extract as a binder [2], pyrrole and 98\% Aldrich. Additional information from this study has already been reported [3], about the electrochemical polymerization in the monomer pyrrole as a component of composite electrodes and the surface modification of the commercial graphite electrode from a $\mathrm{KCl}$ solution as supporting electrolyte both as a working electrode electrochemical sensor. Composites for electrodes were drying at two and twelve hours, to improve the compaction of the composite. The composites for electrodes were mounted in metal holder and the presence of the polymeric layer of pyrrol on electrode and the chemical composition of the working electrode was performed by SEM-EDS in a FESEMJEOL7600F. The microanalysis shows the composition percentages of all existing elements in the inner and outer surface of the sliced pieces of the sensing electrodes, which correspond whit graphite $(\mathrm{C})$, extract nopal $(\mathrm{Mn}, \mathrm{Al})$ and the solution of $\mathrm{KCl}(\mathrm{K}, \mathrm{Cl})$. The outer surface shows the tendency of $\mathrm{Zn}$ ions in greater proportion and $\mathrm{Cd}$ lesser extend to be incorporated into the polymer matrix by ion exchange for susceptibility testing on the electrodes M-3.2 and M-3-3 (Fig.1, 2) and Pt electrode. The $\mathrm{Pb}$ ion occurs only in the electrode $\mathrm{M}-0$ (Fig.3) and $\mathrm{Cu}$ only in the E-Pt electrode (Fig. 4). The morphological characterization by SEM shows the presence of the polymer pyrrole films on the surface of the electrodes. The SEM and EDS results allow conclude that is possible achieve polymerization over the surface of graphite, being the composite electrode 3-2 with longer drying time which achieve better compaction and less porosity, and metals ions are incorporated into the polymeric matrix, possibly ion exchange possible during the screening test. 


\section{References}

[1] M. Cortés, et al., Revista colombiana de física, 38 (4) (2006).

[2] C. Sáenz, Boletín de servicios agrícolas de la FAO, 162 (2006) 106.

[3] H. Quintana, et al., Conference proceedings SMEQ, MES-001 (47) (2012)
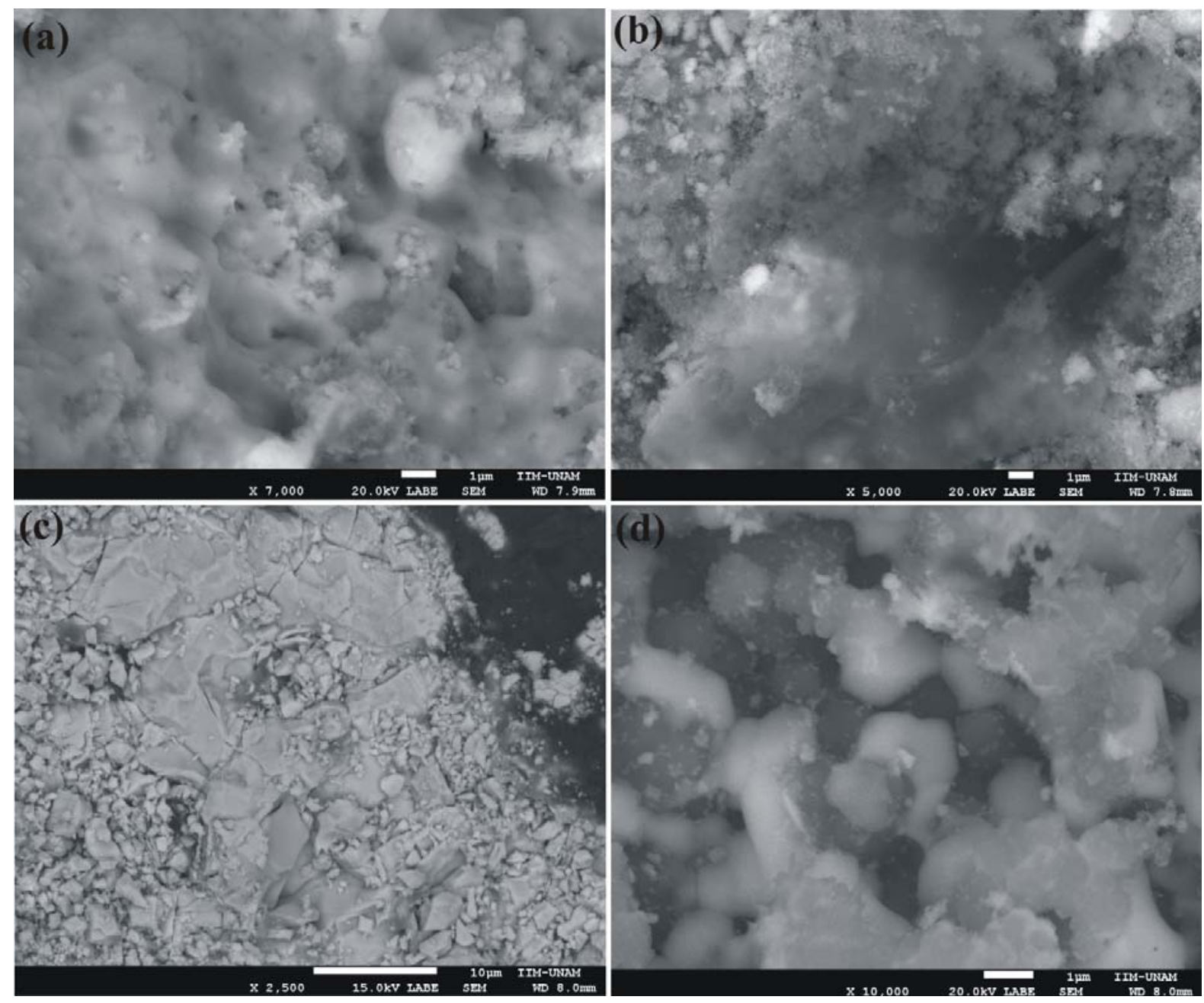

Figure 1. SEM micrographs of the composites electrodes, subjected to $\mathrm{KCl}$ and solutions of heavy metals. (a). M-3.2 consisting of graphite + Opuntia Ficus extract + Pyrrole, $12 \mathrm{~h}$ drying. (b) M-3.3 composed of graphite + Opuntia Ficus extract + Pyrrole, 2 h drying. (c) M-0 composed of graphite + pyrrole. (d) E-Pt consisting of polipyrrol from platinum sheet.

Copyright agreement

Authors are agree that if accepted, the copyright of the paper will be transferred to the Microscopy Society of America. 